\title{
DOS PLACAS BRONCÍNEAS CON DECORACIÓN GRABADA, DE ÉPOCA TARDORROMANA
}

POR

\author{
JOSÉ BELTRÁN FORTES \\ Universidad de Sevilla
}

\section{RESUMEN}

Se estudian dos placas de bronce que presentan una decoración incisa en la cara frontal: un felino (pantera o leona) y un sátiro sobre un delfín. El análisis estilístico lleva a concluir su elaboración durante la segunda mitad del siglo IV d.C., seguramente en un taller extrahispano, quizá de la Italia central.

\section{SUMMARY}

The incised decoration on two bronze plaques is discussed: a panther or lioness and a satyr on a dolphin. They are dated by style to the second-half of the 4th century AD. They are the product of a non-Iberian Peninsula workshop, probably to be located in Central Italy.

El estudio de materiales arqueológicos que proceden de hallazgos fortuitos o que forman parte de colecciones particulares tiene el evidente inconveniente de que no contamos con la fundamental referencia de los contextos de los que formaban parte, disponiendo en muchos casos sólo de referencias generales de procedencia, de las que nunca se tiene en el fondo constancia cierta; éste es el caso de dos pequeñas placas broncíneas, que debieron aparecer en fecha indeterminada en tierras andaluzas y que forman parte en la actualidad de una colección particular malagueña ${ }^{1}$. Con base en la similitud formal y estilística de ambas piezas debieron formar parte de la decoración de un mismo objeto: en efecto, presentan ambas en cada uno de los cuatro ángulos una perforación en forma de I, e incluso se conserva en

${ }^{1}$ Este trabajo fue elaborado en Roma, en la Escuela Española de Historia y Arqueología, como parte de una estancia subvencionada por la DGICYT (Ministerio de Educación y Ciencia), a la que manifestamos nuestro agradecimiento. Las piezas se encuentran en la colección de D. José Fernández Llamazares (Ronda, Málaga) y, según sus referencias, procederían de un amplio sector entre las actuales provincias de Málaga, Córdoba y Sevilla, sin más precisión. Nuestro agradecimiento a D. Miguel Puya por indicarnos su existencia, así como a Dña. Elizabeth Candon por la elaboración de los dibujos. una de ellas aún una pequeña lámina, asimismo metálica, doblada sobre sí misma y que se introduce en la perforación, para sujetar la placa al objeto correspondiente. Dado que los dos extremos de la laminilla conservada también se doblan en sentido contrario en sus extremos (fig. 5-1, sección A-B), podemos pensar que el objeto al que se unían pudo tratarse de una fina plancha metálica o de madera, o incluso de un material más blando, como cuero ${ }^{2}$, pero en cualquier caso no es posible determinar su finalidad.

Pieza $n^{\circ} 1$ (figs. 1, 2 y 5-1): Placa broncínea, de forma cuadrada, de $5,30 \mathrm{~cm}$ de lado y $0,02 \mathrm{~cm}$ de grosor, que tiene una pequeña pérdida en la esquina superior izquierda, así como una rotura en el lado inferior. Como se ha dicho, presentaba en cada uno de los ángulos una perforación y, en la inferior izquierda, aún conserva in situ la lámina para su ajuste (cfr. fig 5-1, sección A-B). La decoración se restringe a una de las caras, delimitándose un contorno mediante sendas acanaladuras paralelas en cuyo interior se ha representado, mediante incisiones, la figura de un felino (una leona o pantera moteada) representado de perfil, en salto hacia la derecha. El resto del espacio está ocupado por la

${ }^{2}$ Una interesante hipótesis, teniendo en cuenta el tamaño de las placas, sería el de considerarlas segmenta metálicos de un cingulum, ya que sobre todo a partir del siglo III d.C. deja de ser un elemento típicamente militar (Kunzl 1977; BoubePicot 1994) y se extiende al campo civil como un importante elemento representativo (Warland 1994). No obstante, en general, en las producciones del siglo Iv d.C. no encontramos paralelos adecuados; así, o bien se elaboran en opus interrasile y con contornos de grandes perlas (no sólo en talleres orientales, Heurgon 1958, sino también en occidentales, Baratte 1979), o bien se imponen las producciones occidentales con decoración según esquemas geométricos a base de técnica excisa (Bullinger 1969; Böhme 1974; Sommer 1984). Para Hispania, Pérez, Viñe 1990; Pérez 1992. Vera (1994) recoge un ejemplar de Zuheros (Córdoba). Por otro lado, no olvidemos que - asociadas al cuero- también eran adecuadas las placas broncíneas para otros usos, como, por ejemplo, en atalajes de caballerías (Boube-Picot 1980). En general, para pequeños bronces hispanos tardorromanos, $\mathrm{cfr}$. Caballero 1974; Fuentes 1990. 


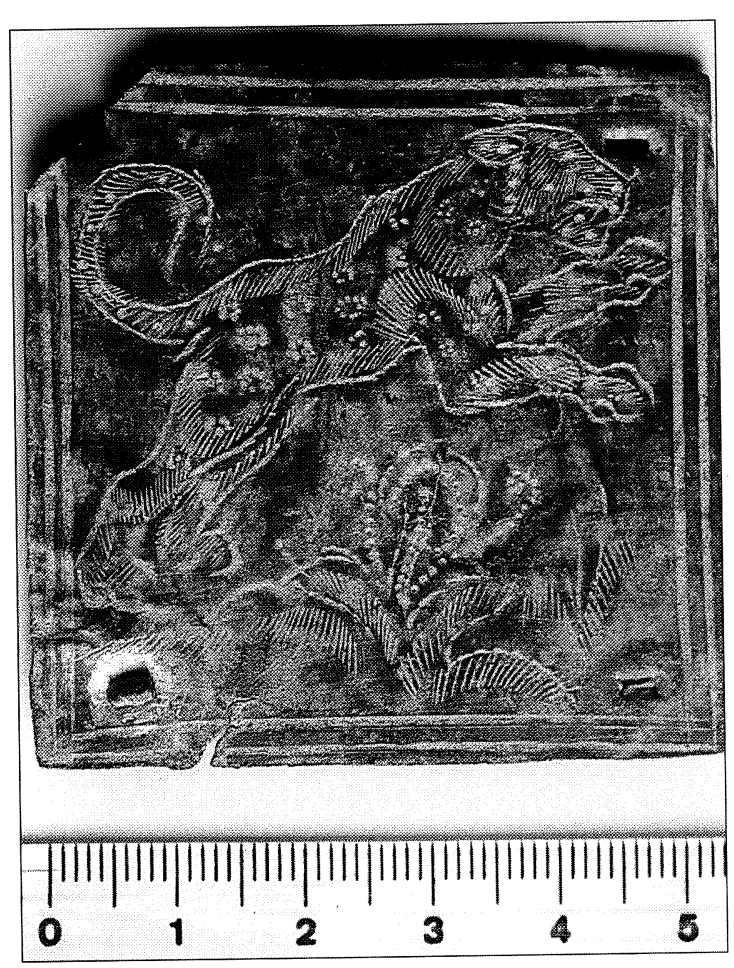

Fig. 1.-Placa de bronce decorada con pantera o leona $\left(n^{\circ} 1\right)$. Colección particular (Ronda, Málaga). Cara frontal.

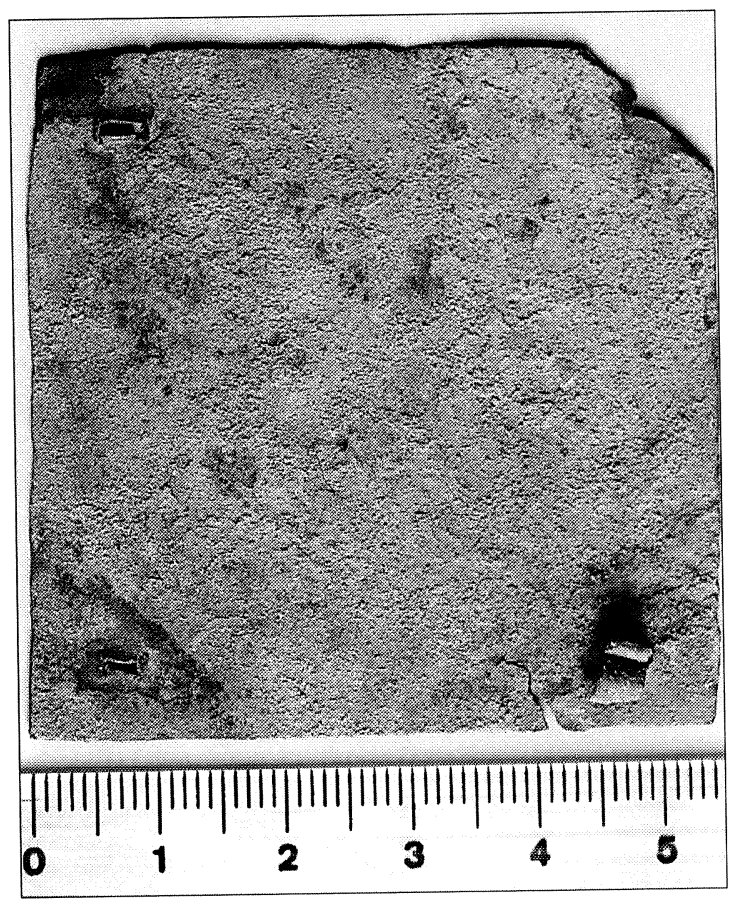

Fig. 2.-Idem. Cara posterior. representación esquemática del suelo, junto a un motivo vegetal, con una flor o capullo en su centro, dispuesto entre finos tallos espiraliformes.

Pieza $n^{o} 2$ (figs. 3, 4 y 5-2): De idéntico material, esta plaquita se dispone en forma rectangular, con $5,30 \mathrm{~cm}$ de altura, $5 \mathrm{~cm}$ de anchura y $0,02 \mathrm{~cm}$ de grosor. También tiene una rotura en la parte superior izquierda y las cuatro perforaciones en las esquinas. En este caso, en el interior del marco de doble acanaladura se ha representado una figura humana, desnuda y barbada, que cabalga sobre un delfín; el personaje coge con su mano izquierda las bridas, mientras que con el brazo contrario sujeta en alto un látigo. El resto del espacio se ocupa con simples incisiones que representan bien el cielo, bien las aguas marinas. En la composición es de destacar, no obstante, la colocación casi de tres cuartos, de espaldas, del sátiro, lo que le da lógicamente una mayor sensación de profundidad.

El elemento más sobresaliente lo constituyen sin duda las características iconográficas y estilísticas (sobre las que vamos a incidir aquí) de los motivos decorativos, lo que da pie a establecer algunas conclusiones de orden cronológico y del taller de elaboración ${ }^{3}$. Desde el punto de vista técnico la decoración se realiza en su totalidad mediante un grabado inciso en el que se reconocen tres tipos de incisiones. En primer lugar, unas incisiones más profundas y cortas, enlazadas entre sí para formar una serie de líneas de los contornos de las figuras principales; en segundo lugar, incisiones menos profundas y más alargadas, que sirven para una especie de «sombreado» secundario; y, finalmente, una serie de puntos o líneas de puntos que sobre todo se emplean en la primera placa (cuerpo del felino y capullo vegetal), en contraposición a su escaso empleo en la segunda (látigo y bridas). Los instrumentos serían punzón o buril y martillo, aunque para los puntos parece aconsejable un utensilio de punta redondeada ${ }^{4}$. No quedan rastros de dorado o plateado posterior, como ocurre en otras ocasiones $^{5}$.

${ }^{3}$ Hemos analizado la originalidad iconográfica del motivo del sátiro sobre el delfín en Beltrán 1995; cfr. infra notas 24-28.

4 Para tales aspectos técnicos, cfr. Carandini 1965, 6 ss.; Arce 1982.

5 No obstante, Arce $(1982,125)$ recuerda que la superficie de la sítula de Bueña presentaba una fina película de plata que saltaba limpiamente, por lo que no era nielada, sino que o bien había sido fijada mediante un adhesivo, o bien empleando mercurio y calentando la pieza con posterioridad para fijar la plata. Cfr., por ejemplo, Stefanelli 1990, 33 ss. 


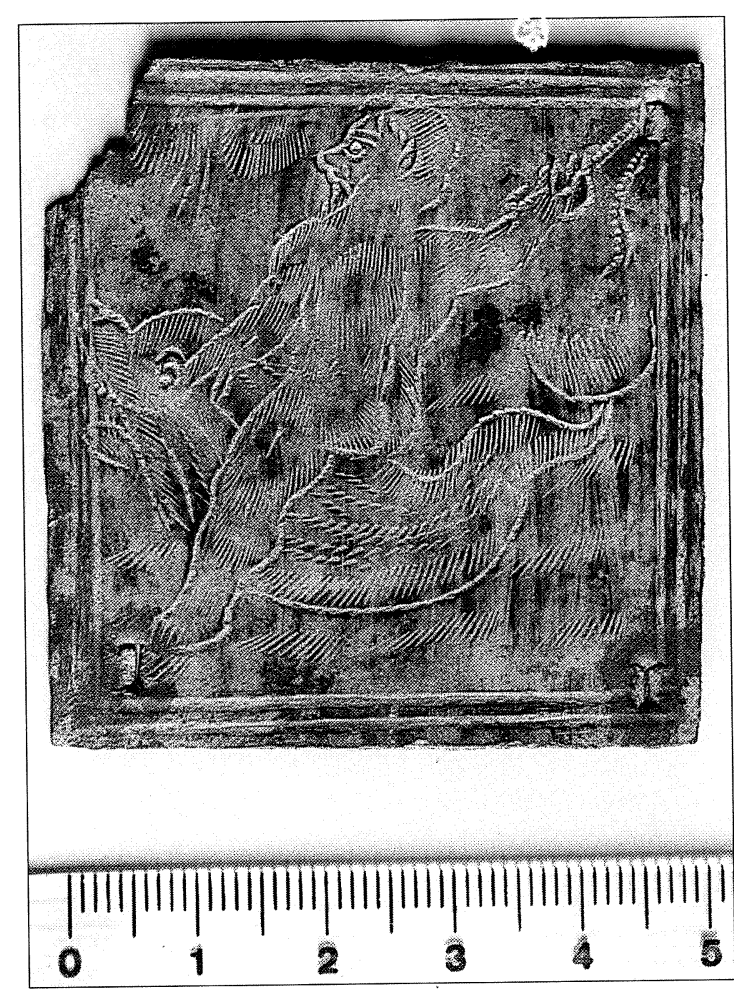

Fig. 3.-Placa de bronce decorada con sátiro sobre delfín $\left(n^{\circ} 2\right)$. Colección particular (Ronda, Málaga). Cara frontal.

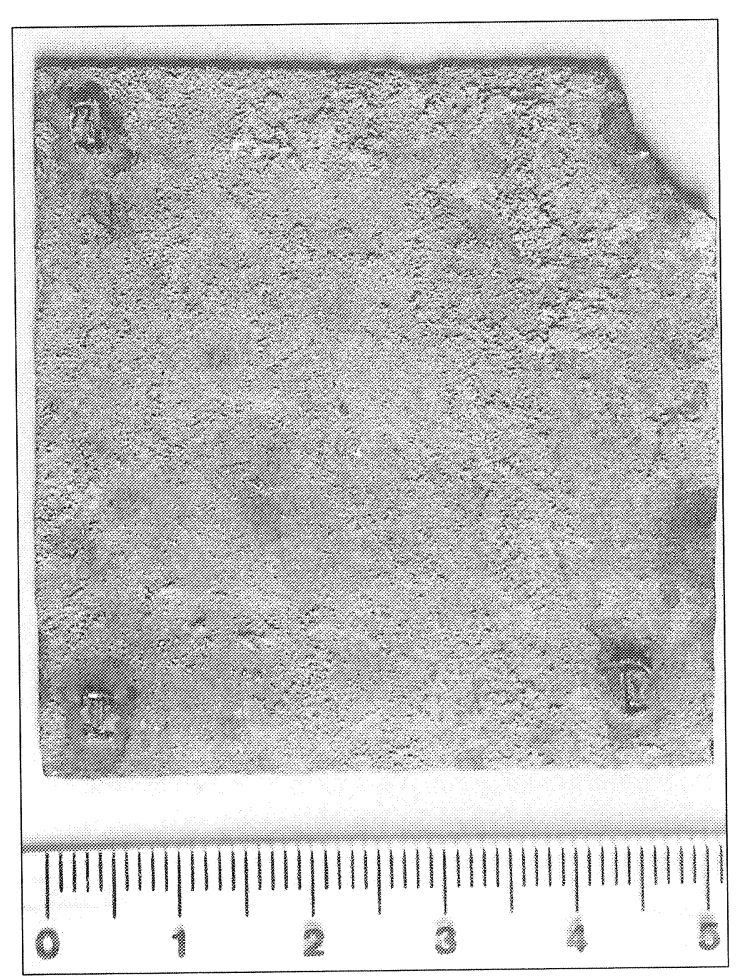

Fig. 4.-Idem. Cara posterior.
La técnica exclusiva del grabado y, sobre todo, el estilo decorativo con contornos hechos a base de cortas y profundas incisiones y abundancia de detalles internos son características propias de esquemas ornamentales de época tardorromana, sobre todo a partir del siglo Iv d.C. ${ }^{6}$, y se documentan asimismo en objetos de plata ${ }^{7}$ y en otros ámbitos artísticos, como en la decoración de hueso, marfil, cerámica, etc. ${ }^{8}$. De todas formas, una técnica similar se sigue empleando con posterioridad - al menos durante los siglos v y vi d.C. - también en objetos de bronce. Para ello contamos con una pieza de procedencia hispana, la sítula de Bueña (Teruel), aunque es claramente un objeto de importación dentro de la serie de calderos broncíneos elaborados en un ámbito de talleres del Mediterráneo oriental — seguramente ubicados en el territorio egipcio-, desde mediados del siglo v d.C. hasta mediados del siglo vi d.C., entre los que podemos mencionar, además, la Secchia Doria y los ejemplares del Ashmolean Museum de Oxford, de Chessel Down y de Zerzevan ${ }^{9}$.

No obstante, los mejores paralelos estilísticos y formales para nuestra decoración se encuentran asimismo en objetos de bronce del siglo IV d.C., que se han vinculado, en general, a un ámbito de taller centro-mediterráneo. Debemos mencionar, en primer lugar, la sítula, datada por Carandini en el segundo cuarto del siglo IV d.C., de procedencia desconocida - pero adquirida en el comercio de antigüedades de Roma- y hoy conservada en los Museos Capitolinos tras su paso por el Antiquarium Comunale ${ }^{10}$. Se trata de un caldero de forma troncocónica, con dos anillos a medio relieve que subdividen la superficie externa en tres frisos, decorados con incisiones a punzón, en los que se desarrolla un

${ }^{6}$ Lipinski 1975,235 . Es también característica la incrustación de plata o cobre sobre el bronce silueteado (Bielefeld 1972, 426 ss.). Cfr. infra notas 19-21.

7 En principio se asocia el repujado con la incisión, según una técnica que se constata también en el siglo IV d.C. (como en el tesoro de Kaiseraugst: Laur-Belart 1964; Manacorda 1972; AA.VV. 1987). En otros casos sólo aparecen motivos incisos, como, por ejemplo, en algunas piezas del tesoro de Notre-Dame-d'Allençon (Baratte 1981, $\mathrm{n}^{\text {os }} 7-9$ ).

8 Salomonson 1973, 3 ss.; Volbach 1962; Volbach 1976; Albertoni 1994.

9 Todo el conjunto fue estudiado por Arce 1982. Como indica Carandini (1965, 6 ss.), se constatan en estas sítulas otras dos técnicas, aparte de las tres documentadas en nuestras placas: el «ferro a perla», para realizar pequeños círculos, y el «granitoio» redondo, que modelaba la superficie de las figuras, creando una clara diferencia con el fondo liso y originalmente dorado. Además, se advierten variantes estilísticas en el conjunto.

${ }^{10}$ Carandini 1963-64. Nuestro agradecimiento a la Dirección del Museo, que nos permitió un análisis directo y la documentación gráfica. 

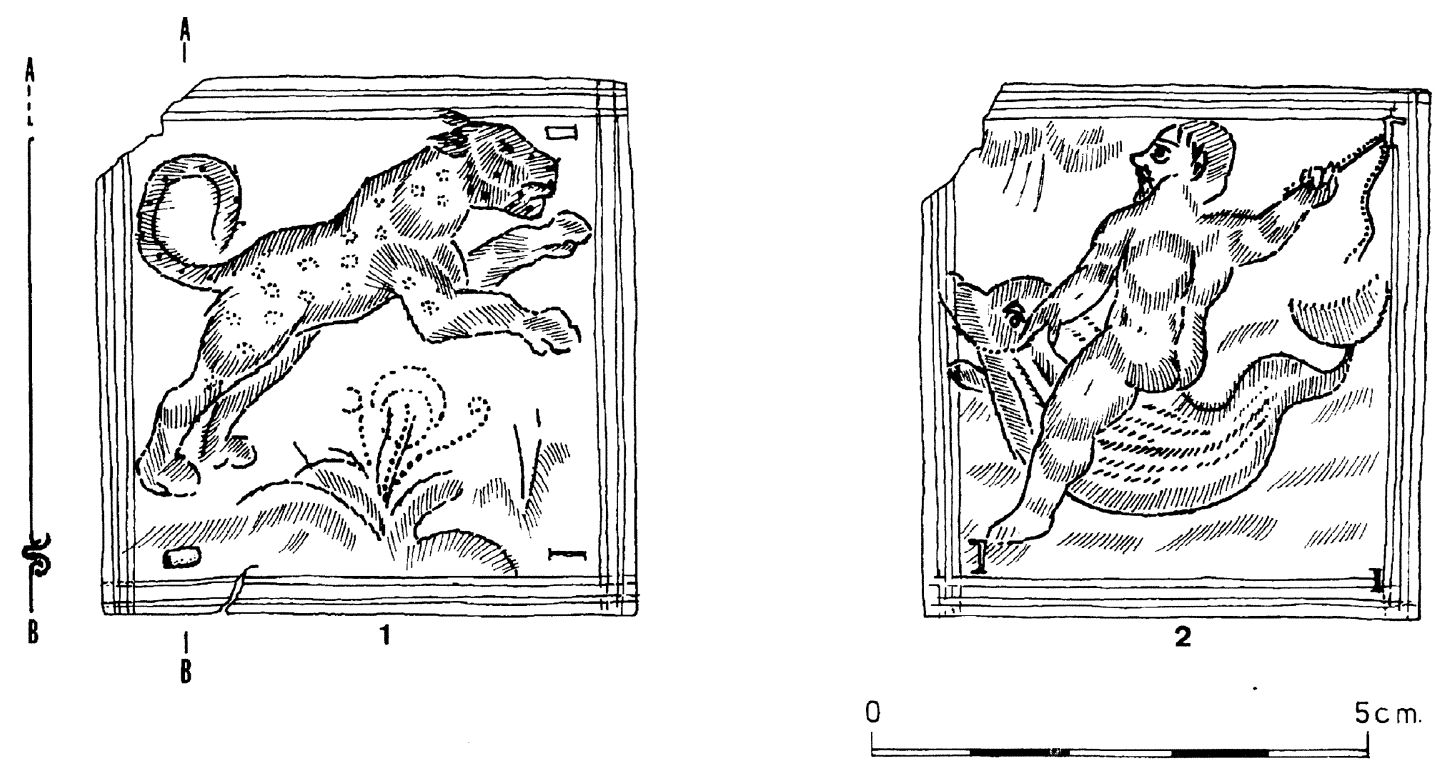

Fig. 5.-Dibujo de la decoración frontal de ambas placas (según E. Candon), y sección A-B de la placa nº 1 .

motivo de thiasos marino - en el superior- y, en los otros dos inferiores, paisajes de villae marítimas y escenas de pesca (fig. 6), con un verdadero horror vacui que inunda de diferentes tipos de peces el espacio disponible. Es destacable la similitud técnica y estilística con la decoración de nuestras placas, ya que se hace uso frecuente de las series de trazos a buril para crear ese denominado «sombreado», asociado a las líneas de contornos mediante golpes cortos y enlazados. Carandini, tanto por detalles anticuarios - los tipos de la fauna marina, que se documentarían sobre todo en el repertorio musivario norteafricano ${ }^{11}$-, como por consideraciones es-

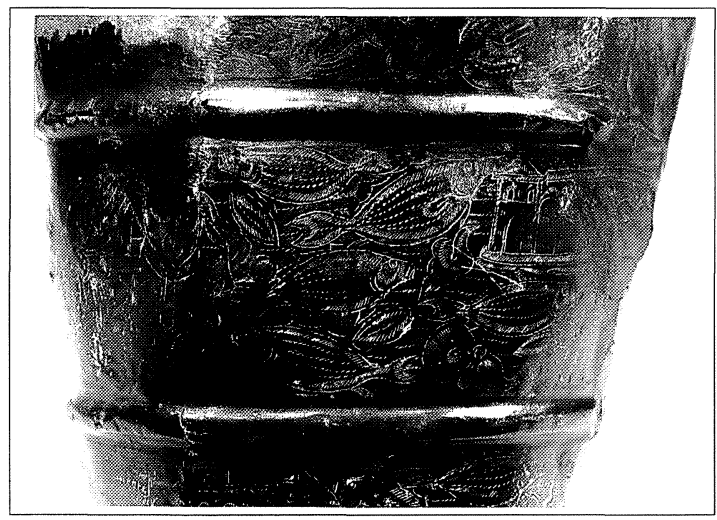

Fig. 6.-Sítula de bronce de Roma. Detalle de la parte central. Museos Capitolinos, Roma (Fotografía: Museo).

$"$ Sobre los mosaicos norteafricanos cfr. Dunbabin 1978. tilísticas, en función del estilo del grabado, alejado del naturalismo pictórico de tradición aún helenística propio de los talleres orientales, concluía que la decoración de la sítula está vinculada al «arte del bacino meridionale del Mediterraneo occidentale in un momento storico non lontano dal secondo quarto del IV secolo» ${ }^{12}$. No obstante, consideraba asimismo posible la elaboración de piezas como ésta en ámbito itálico, pero por un artesanado de cultura norteafricana, en función del desarrollo de una común cultura italo-africana, desde Constantino y hasta mediados del siglo $\mathrm{v}$ d.C., donde eran especialmente estimados los temas de cacería y mitológicos que aún mantenían los modelos clásicos ${ }^{13}$.

En todo caso, a ese ámbito centroitálico apuntan también otra serie de objetos broncíneos del siglo IV d.C. paralelizables con la sítula analizada y con nuestras placas. Destaca especialmente una patera broncínea, encontrada en los alrededores de la catacumba de Pretextato y conservada actualmente en el Museo Nazionale Romano ${ }^{14}$, que presentaba en el interior una decoración de máscara de Oceanus -en el centro- y escenas de pesca alrededor (fig. 7) en las que sobresalen, con el mismo sentido del horror vacui, las representaciones de peces con algún delfín. Desde el punto de vista estilístico destaca asimismo la presencia abundante de «sombrea-

\footnotetext{
12 Carandini 1963-64, 162.

13 Carandini 1961-62, 69 s.; Carandini 1963-64, 163.

14 Cfr. Salomonson 1973, 75, figs. 59-62. Nuestro agradecimiento a la Dirección del Museo por habernos permitido el
} análisis directo de la pieza y por las fotografías. 


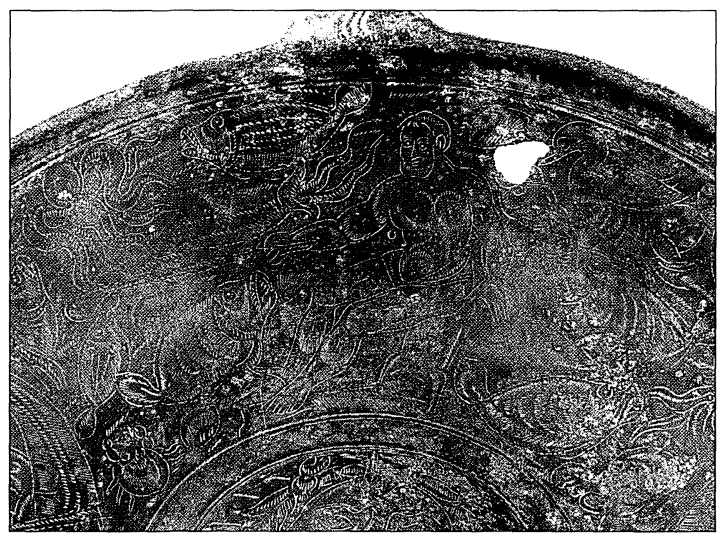

Fig. 7.-Patera de bronce de la catacumba de Pretextato, Roma. Detalle de la decoración interior. Museo Nazionale Romano (Fotografía: Museo).

do» a base de grupos de trazos de incisiones cortas, que se asocian a líneas más profundas de contorno, siendo el punteado sólo un recurso secundario.

Otros ejemplares, que se relacionan con ese centro (o centros) de producción de ámbito centroitálico - seguramente en Campania o en la propia Roma ${ }^{15}$-, no presentan ya una similitud estilística tan acusada. En algunos casos falta el característico «sombreado», como ocurre, por ejemplo, en el plato broncíneo de Anzio, que decora el fondo interior con la representación de una villa marítima y el resto con escenas de pescadores ${ }^{16}$, o con otra pieza aparecida en Roma, pero hoy en el Metropolitan Museum de New York, cuya finalidad es incierta quizá para decorar la parte delantera de la cabeza del atalaje de cuero de un caballo- y que se decora con tres escenas relativas a Leda ${ }^{17}$ (fig. 8).

En otros casos es fundamental la abundancia del uso del punteado, como ocurre en una placa de Rocca di Papa, conservada en el Museo Nazionale Romano ${ }^{18}$, con una escena de dextrarum iunctio, que quizá pudo tener una cronología algo más avanzada, pero en todo caso dentro del siglo IV d.C. ${ }^{19}$.

Podemos también testimoniar algunas otras piezas broncíneas del siglo IV d.C. que presentan un

\footnotetext{
15 Salomonson 1973,75 ss.

16 También lo recoge Salomonson 1973, 37, fig. 26, que lo considera de la primera mitad del siglo IV d.C.

17 Bell, en Weitzmann 1979, 239 s., n ${ }^{\circ} 215$ : de 0,26 x 0,19 $\mathrm{cm}$, cuyo mejor paralelo formal sería la denominada «placa de Briseida» (escenas de Aquiles y Briseida), del British Museum, pero también procedente de Italia (ibid., $218 \mathrm{~s}$, $\left.\mathrm{n}^{\circ} 195\right)$.

18 Salomonson 1973, 35 s., fig. 25. También Carandini 1963-64, 163

${ }_{19}$ Otros ejemplos proceden de la Italia septentrional (Castoldi 1989 y 1993).
}

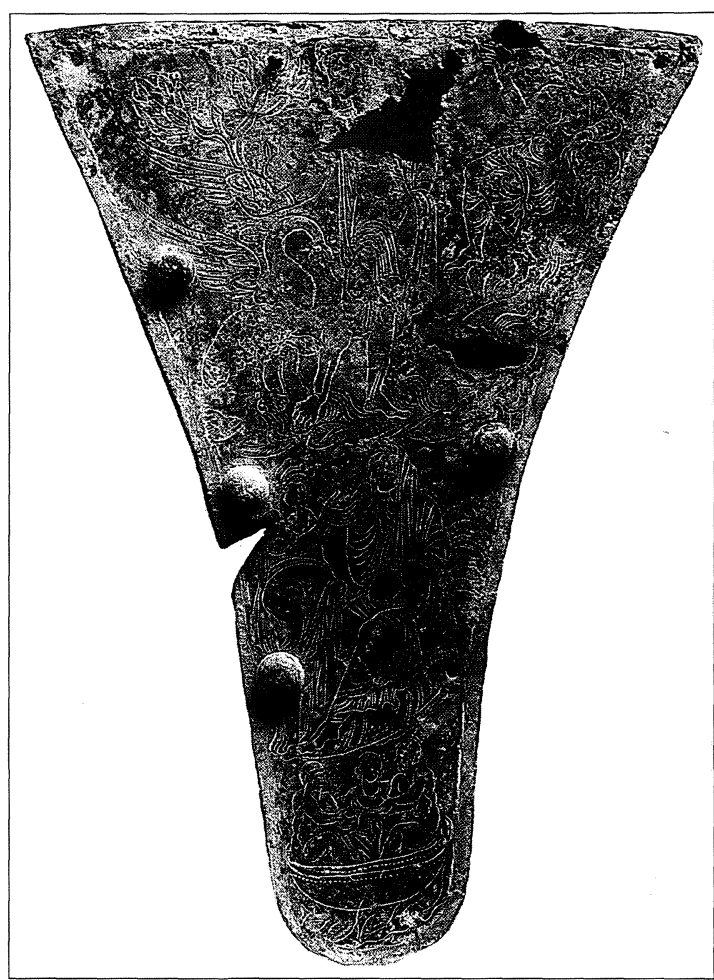

Fig. 8.-Placa de bronce de Roma. Metropolitan Museum, New York (Fotografía: DAI Roma, $n^{\circ}$ neg. 35-1551).

estilo decorativo similar (incisiones y «sombreado») aunque con técnica diferente (incrustaciones de plata dorada sobre siluetas rebajadas en placas broncíneas), como una placa seguramente procedente de Italia, aunque hoy en el Museo del Louvre, con escenas de cacería ${ }^{20}$ (fig. 9). Frente a la idea de que la pieza hubiera sido elaborada en un taller galo ${ }^{21}$, se ha apuntado como más factible su ejecución en un taller también de Italia central ${ }^{22}$, precisamente en relación con los ejemplares que estamos citando.

Los motivos iconográficos de las dos placas andaluzas se ajustan perfectamente, además, a ese conjunto analizado, ya que, aparte de su pertenencia a temas especialmente preferidos en época tardorromana en los elencos ornamentales (como los de carácter marítimo, de cacería o dionisíaco), tienen una especial referencia en algún caso a regiones del norte africano, en especial en el campo musivario ${ }^{23}$. Ya

${ }^{20}$ Zwirn, en Weitzmann 1979, 87 s., no 77 (de 15 x 18,7 $\mathrm{cm}$ ), se data en la segunda mitad de la centuria.

21 Kleinbauer 1976, 22 ss., que además relaciona piezas de técnicas no similares. Cfr. Bielefeld 1972, 426 ss.

22 Salomonson 1973, 30 ss.; asimismo, Zwirn, en Weitzmann $1979,87 \mathrm{~s}$.

${ }^{23}$ Vid. Dunbabin 1978; Guardia 1992. Cfr. supra notas $11-13$. 


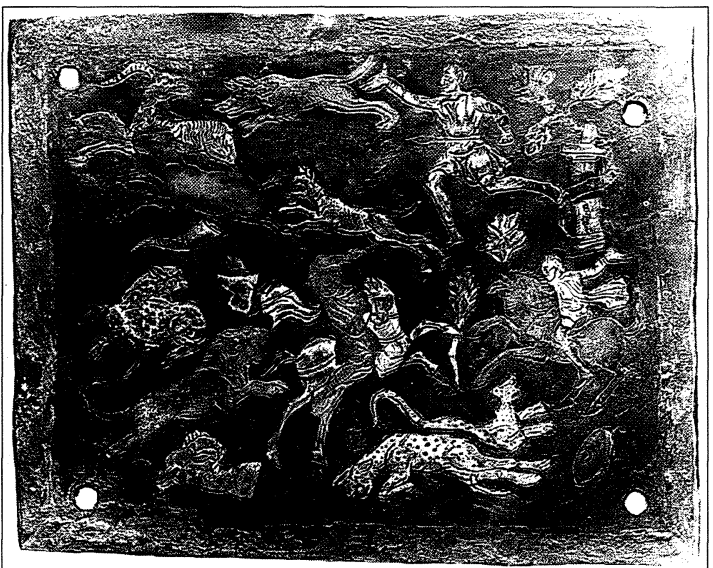

Fig. 9.-Placa de bronce con incrustaciones de plata dorada, de Italia (?). Museo del Louvre (Fotografía: DAI Roma, $n^{\circ}$ neg. 49-43).

hemos analizado en otro trabajo la singularidad iconográfica del tema del sátiro cabalgando al delfín ${ }^{24}$, con muy escasos modelos artísticos ${ }^{25}$, y que, quizá como consecuencia de un gusto erudito - propio de ciertos ámbitos de la cultura tardorromana occidental-, parece rememorar aspectos tales como la relación Baco/mar, a partir de episodios como los del descubrimiento de Ariadna en Naxos ${ }^{26}$ y -más específico- de los piratas tirrenios convertidos en delfines ${ }^{27}$, o la referencia, erudita y culta, al hecho de que tanto delfín y sátiro, por su similitud fisonómica, recibían un nombre común, simós («chato»), como recoge claramente Plinio y se documenta en una serie de autores tardíos, a partir del siglo IV d.C. ${ }^{28}$.

En relación al otro motivo iconográfico, aunque sería atractiva la idea de considerar que se trata de la representación de una pantera báquica — concluyendo por tanto la posible existencia de un programa decorativo común de carácter religioso o ideológico, en relación con lo dionisíaco-, sin embargo, ello nos parece arriesgado a partir de los datos con los que contamos y la descontextualiza-

${ }^{24}$ Beltrán 1995, al que remitimos para un desarrollo más amplio en estos aspectos.

25 Sólo se conocen dos esculturas romanas en las que un sátiro joven está encima del delfín, una de la Galleria Borghese y otra de la Gliptoteca de Munich, aunque el modelo debió surgir en época helenística, durante el siglo II a.C.; Amelung 1900; Ridgway 1970, 92 ss.

26 Arce 1976, 343 ss.

27 Ientile 1983, 33 ss.; Sánchez 1990, 55 ss.

28 Plin. NH IX, VII, 23 ss. Cfr. Stebbins 1929, 5 ss. También, por ejemplo, el tema de Arión sobre el delfín se desarrolla en el campo de la musivaria en relación con los talleres norteafricanos (Carandini 1961-62, 42). ción de las piezas, ya que el felino tampoco presenta la iconografía habitual de la pantera báquica, sino que nos encontramos con una figura de repertorio, propia de escenas cinegéticas de época tardorromana. Así, se documenta también en decoraciones metálicas, como en un oinochoe de plata repujada e incisa, datado en el mismo siglo IV d.C., y donde en una de las bandas decorativas se dispone una pantera con similar actitud ${ }^{29}$. Debemos concluir, pues, que nos encontramos sólo ante dos temas de taller, extraídos del rico acervo clásico disponible para el arte y la literatura grecorromanos y que fue utilizado de forma erudita durante el siglo Iv d.C. en las provincias occidentales.

Dada la ausencia de paralelos formales y estilísticos dentro de las producciones locales de la Hispania tardorromana ${ }^{30}$ y a raíz de los paralelos aportados, consideramos que las dos placas broncíneas andaluzas podrían relacionarse de forma más o menos directa con las producciones elaboradas en los territorios centro-itálicos durante el siglo IV d.C. -en especial en su segunda mitad-, por lo que parece lógico que el objeto que decoraran fuera importado en aquellas fechas. El hecho es plausible teniendo en cuenta las estrechas relaciones mediterráneas mantenidas en ciertas zonas hispanas - como la Bética - durante esa segunda mitad del siglo Iv d.C., y que explicarían perfectamente la presencia de la pieza también como fruto de un comercio de lujo ${ }^{31}$.

\section{BIBLIOGRAFÍA}

- AA.VV., 1987: Il tesoro nascosto. Le argenterie imperiale di Kaiseraugst, Milano-Roma.

- AA.VV., 1997: Figlinae malacitanae, Málaga.

- Albertoni, M., 1994: Inediti frammenti di classicismo tardoantico, Bull. Musei Comunali di Roma, 8, 160 ss.

29 Baratte 1975, fig. 6. También una pantera en salto aparece en la escena de cacería de la sítula del Ashmolean $\mathrm{Mu}$ seum (Arce 1982, lám. 6 a).

${ }^{30}$ Fuentes (1990) ha destacado la preferencia en las decoraciones de piezas broncíneas hispanas del calado y la incisión frente a la excisión.

31 Además de la ya citada sítula de Bueña - aunque del siglo v d.C. (Arce 1982)-, buenos ejemplos de la presencia de objetos de lujo importados durante el siglo IV d.C. los suponen, por ejemplo, los marfiles coptos aparecidos en la villa de Valdetorres de Jarama (Carrasco - Elvira 1994) o una arracada siria procedente de Castulo (Bandera e.p.). Además los envases cerámicos evidencian mejor que cualquier otro elemento arqueológico la intensidad de ese activo comercio mediterráneo durante esa centuria, aunque se concentra en las zonas costeras (cfr., por ejemplo, AA.VV. 1997). 
- Amelung, W., 1900: Satyrs Ritt durch die Wellen, Strena Helbigiana, Lipsiae, 1 ss.

- ArCE, J., 1976: El mito de Dionysos y Ariadna en un puteal tardorromano del Museo de Mérida (Augusta Emerita), Habis, 7, 343 ss.

- ARCE, J., 1982: La sítula tardorromana de Bueña (Teruel), Estudios de Iconografía, I, Madrid, 124 ss.

- Bandera, M. L., en prensa: Arracada siriana en Cástulo (Linares, Jaén), III Congreso Andaluz de Estudios Clásicos, Sevilla.

- Baratte, F., 1975: Vaisselle d'argent au BasEmpire, MEFRA, 87, 1103 ss.

- Baratte, F., 1979: La plaque de ceinture du Coudray: innovation et tradition dans les arts mineurs du Bas-Empire, MonPiot, 62, 43 ss.

- Baratte, F., 1981: Le trésor d'argenterie galloromaine de Notre-Dame-d'Allençon (Maine-etLoire), Paris.

- Bell, M., en Weitzmann 1979, 239 s.

- Beltrán, J., 1995 [1996]: Sátiro cabalgando sobre un delfín. Un tema inusual en la iconografía romana, Arqueólogos, historiadores y filólogos. Homenaje a Fernando Gascó (= Kolaios. Publicaciones Ocasionales 4), Sevilla, 275 ss.

- Bielefeld, E., 1972: Eine Patene aus dem französischen Krönungsschaft. Ein Versuch zur Kleinkunst des 4. Jahrhunderts n. Chr., Gymnasium, 79, 395 ss.

- Böнme, H. W., 1974: Germanische Grabfunde des 4. bis 5. Jahrhunderts, München.

- Boube-Picot, Ch., 1980: Les bronzes antiques du Maroc. III. Les chars et l'attelage, Rabat.

- Boube-Picot, Ch., 1994: Les bronzes antiques du Maroc. IV. L'équipement militaire et l'armement, Paris.

- Bullinger, H., 1969: Spätantike Gürtelbeschläge, Brugge.

- Caballero, L., 1974: La necrópolis tardorromana de Fuentespreadas (Zamora). Un asentamiento en el valle del Duero, EAE 80, Madrid.

- Carandini, A., 1961-62: Ricerche sullo stile e la cronologia dei mosaici della villa di Piazza Armerina, St. Misc. 7, Roma.

- Carandini, A., 1963-64: La situla tardorromana dell' Antiquarium Comunale, BullCom, 79, 147 ss.

- CARAndini, A., 1965: La Secchia Doria: una «storia di Achille»tardoantica, St. Misc. 9, Roma.

- Carrasco, M. - Elvira, M. A., 1994: Marfiles coptos en Valdetorres de Jarama (Madrid), AEspA, 67, 201 ss.

- Castoldi, M., 1989: Recipienti di bronzo tardoromani da Milano, NotMilano, 48-49, 61 ss.
- Castoldi, M., 1993: Bottiglia in bronzo tardo romana decorata da una collezione privata lombarda, Bronces y Religión Romana. Actas del XI Congreso Internacional de Bronces Antiguos, Madrid, 133 ss.

- Dunbabin, K. M. D., 1978: The Mosaics of Roman North Africa. Studies in Iconography and Patronage, Oxford.

- Fuentes, A., 1990: Los bronces bajoimperiales en Hispania, Los Bronces Romanos en España, Madrid, 117 ss.

- Guardia Pons, M., 1992: Los mosaicos de la Antigüedad tardía en Hispania. Estudios de iconografía, Barcelona.

- Heurgon, J., 1958: Le Trésor de Ténès, Paris.

- Ientile, M. G., 1983: La pirateria tirrenica, Roma.

- Kleinbauer, W. E., 1976: A Byzantine Revival: the Inland Bronze Doors at Constantinople, Archaeology, 29, 16 ss.

- Kunzl, E., 1977: Cingula di Ercolano e Pompei, Cronache Pompeiane, 3, 177 ss.

- Laur-Belart, R., 1964: Der spätrömische Silberschatz von Kaiseraugst. Katalog, Basel.

- LiPINSKI, A., 1975: Oro, argento, gemme e smal$t i$, Firenze.

- Manacorda, M. A., 1972: La paideia di Achille, Roma.

- Pérez, F. - Viñe, A., 1990: Los cingula militiae tardorromanos y el inicio de la presencia de tropas de origen germánico en Hispania en los siglos IV y v, Norba, 10, 95 ss.

- Pérez, F., 1992: Los cingula militiae tardorromanos de la Península Ibérica, BSAA, 58, 58 ss.

- Ridgway, B. S., 1970: Dolphins and DolphinRiders, Archaeology, 23, 86 ss.

- Salomonson, J. W., 1973: Kunstgeschichtliche und ikonographische Untersuchungen, BABesch, 48, 3 ss. y 75 ss.

- Sánchez, F., 1990: El dios arrebatado. Una aproximación al problema de la piratería tirrénica en el Egeo, Málaga (tesis doctoral en microficha).

- Sommer, M., 1984: Die Gurtel und Gurtelbeschlage des 4. und 5. Jahrhunderts im römischen Reich, Bonn.

- Stebbins, E. B., 1929: The Dolphin in the Literature and Art of Greece and Rome, Menasha.

- Stefanelli, L. P. B. (ed.), 1990: Il bronzo dei romani. Arredo e suppellettile, Roma.

- Vera, J. C., 1994: Un nuevo testimonio arqueológico sobre la presencia efectiva de contingentes militares centroeuropeos en la Hispania bajoimperial: una hebilla de cingulum mili- 
tia procedente del sur de Córdoba, Antiquitas, 5, 69 ss.

- Volbach, W. F., 1962: Silber und Elfenbeiarbeiten vom Ende des 4. bis Anfang des 7. Jhs., Akten des VII Int. Kongress für Frühmittelalterforschung, 21 ss.

- Volbach, W. F., 1976: Elfenbeinarbeiten der Spätantike und des frühen Mittelalters, Mainz.
- Warland, R., 1994: Status und Formular in der Repräsentation der spätantiken Führungsschidt, $R M, 101,175$ ss.

- Weitzmann, K. (ed.), 1979: Age of Spirituality. Late Antique and Early Christian Art. Third to Seventh Century, New York.

- Zwirn, S. R., en Weitzmann 1979, 87 s. 